OPEN ACCESS

ISSN 2528-4649 (online) ISSN 2338-4409 (print)

Reviewed by: Wisnu Panggah Setiyono \& Anis

Eliyana \& Irwan Moridu

*Correspondence:

Received: 25 Juli 2020 Accepted: 27 Agustus 2020 Published: 30 September 2020

Citation:

Al Azis MS and Harsono S (2020)

Pengaruh Citra Merek,

Kepercayaan Merek dan Sikap

Merek terhadap Minat Menjadi Nasabah Tabungan dan Giro Bank Panin (Studi pada Bank Panin KCP

Tambak Langon Surabaya).

JBMP. 6:2

doi: 10.21070/jbmp.v6i2.672

\section{Pengaruh Citra Merek, Kepercayaan Merek dan Sikap Merek terhadap Minat Menjadi Nasabah Tabungan dan Giro Bank Panin (Studi pada Bank Panin KCP Tambak Langon Surabaya)}

\author{
Mochamad Syaifudin Al Azis, Soni Harsono \\ Program Magister, STIE Perbanas Surabaya, Indonesia
}

The purpose of this study is examine the effect of brand image, brand trust and brand attitude on customer interest of being a savings and current account customer Panin Bank at Branch Office Tambak Langon Surabaya. This research hypothesis states that brand image, brand trust and brand attitude influences customer interest. Data in this study are primary data obtained directly from 170 respondents through questionnaires.From the data obtained then the validity test, reliability test using PLS software. The result of this study indicate that the brand image has asignificant positive effect on customer interest in becoming a savings and current customer at the Tambak Langon Surabaya branch office. brand trust has asignificant positive effect on customer interest in becoming a savings and current customer at the Tambak Langon Surabaya branch office. brand attitude has asignificant positive effect on customer interest in becoming a savings and current customer at the Tambak Langon Surabaya branch office.

Keywords: Brand Image, Brand Trust, Brand Attitude, Interest In Being A Customer

Tujuan Penelitian ini adalah untuk menguji pengaruh citra merek, kepercayaan merek dan sikapmerek terhadap minat menjadi nasabah tabungan dan giro Bank Panin pada KCP Tambak Langon Surabaya. Hipotesis penelitian ini menyatakan bahwa citra merek, kepercayaan merek dan sikap merek berpengaruh terhadap minat menjadi nasabah. Data dalam penelitian ini adalah data primer, yang diperoleh secara langsung dari 170 responden melalui kuisioner. Dari data yang diperoleh kemudian dilakukan uji validitas, uji reliabilitas dengan menggunakan software PLS. Hasil dari penelitian ini menunjukkan bahwa citra merek berpengaruh positif signifikan terhadap minat menjadi nasabah tabungan dan giro Bank Panin KCP Tambak Langon Surabaya, kepercayaan merek berpengaruh positif signifikan terhadap minat menjadi nasabah tabungan dan giro Bank Panin KCP Tambak Langon Surabaya, Sikap merek berpengaruh positif signifikan terhadap minat menjadi nasabah tabungan dan giro Bank Panin KCP Tambak Langon Surabaya. 
Kata Kunci: Citra Merek, Kepercayaan Merek, Sikap Merek, Minat Menjadi Nasabah 


\section{PENDAHULUAN}

Pada era Globalisasi persaingan bisnis antar Bank semakin ketat. Bank yang ingin terus berkembang dan meningkat harus mampu memberikan produk yang berkualitas. Namun, untuk menjadi Bank yang unggul dalam persaingan bukanlah sebuah hal yang mudah, diperlukan pengelolaan manajemen yang bagus dan berkualitas. Selain itu dibutuhkan pula strategi yang maksimal.

Menurut UU RI No.10 1998, Bank merupakan badan usaha yang menghimpun dana dari masyarakat dalam bentuk simpanan dan menyalurkannya kepada masyarakat dalam bentuk kredit dan atau bentuk-bentuk lainnya dalam rangka meningkatkan taraf hidup masyarakat banyak. OJK mencatat hingga akhir Desember 2018, ada sebanyak 115 Bank di Indonesia dengan komposisi ada 5 Bank BUKU IV dan menguasai $51,03 \%$ asset perbankan. Bank BUKU III ada 28 Bank dengan pengusaan asset $35,23 \%$. Bank BUKU II sebanyak 59 Bank dengan pangsa asset 12,65\% dan Bank BUKU I sebanyak 22 Bank dan penguasaan asset hanya 1,08\%. Di antara Bank tersebut, terdapat Bank Panin yang didirikan pada tahun 1971 yang merupakan hasil dari merger dari 3 Bank, yaitu Bank Kemakmuran, Bank Industri Jaya dan Bank Industri Dagang Indonesia. Berdasarkan data keuangan per September 2018, Bank nasional dengan asset tertinggi masih disematkan pada Bank BRI, peringkat ke dua terdapat Bank Mandiri, diikuti secara berututan Bank BCA, Bank BNI, Bank BTN, Bank CIMB Niaga, Bank Panin, Bank OCBC NISP, Bank Maybank dan Bank Permata.

Selain citra merek dan kepercayaan merek, sikap merek juga merupakan faktor yang dapat mempengaruhi minat beli konsumen. Sikap terhadap merek ditampilkan sebagai fungsi ganda dari kepercayaan yang terpenting yang dimiliki konsumen tentang suatu merek dan juga penilaian evaluative dari kepercayaan itu Maksudnya,seberapa baik dan buruk atribut yang dimiliki oleh suatu merek (Kurniawati, 2009).

Tujuan yang ingin dicapai dalam penelitian ini untuk menguji signifikasi citra merek terhadap minat menjadi nasabah tabungan dan giro pada Bank Panin KCP Tambak Langon Surabaya, untuk menguji signifikasi kepercayaan merek terhadap minat menjadi nasabah tabungan dan giro pada Bank Panin KCP Tambak Langon Surabaya, untuk menguji signifikasi sikap merek terhadap minat menjadi nasabah tabungan dan giro pada Bank Panin KCP Tambak Langon Surabaya, untuk menguji pengaruh citra merek, kepercayaan merek dan sikap merek terhadap minat menjadi nasabah tabungan dan giro pada Bank Panin KCP Tambak Langon Surabaya

\section{METODE}

Penelitian ini dilakukan untuk menguji hipotesis dengan maksud dapat memperkuat teori yang dijadikan pijkan. Berkaitan dengan hal tersebut maka jenis penelitian yang digunakan adalah penelitian penjelasan (Explanatory Research) atau penelitian yang bersifat menjelaskan. Artinya penelitian ini menekankan pada hubungan antar variable penelitian dengan menguji hipotesis (Supardi, 2013:20).

Penelitian ini meneliti pengaruh citra merek, sikap merek dan kepercayaan merek terhadap minat menjadi nasabah tabungan dan giro. Adapun ruang lingkup dalam penelitian ini adalah hanya ditujukan kepada nasabah tabungan dan giro di Bank Panin KCP Tambak Langon Surabaya.

Variabel yang akan dianalisis dalam penelitian ini adalah Variabel independen Citra Merek, Kepercayaan Merek, Sikap Merek, Sedangkan Variabel dependen Variabel dependen adalah Minat Menjadi Nasabah. Analisa yang digunakan dalam metode ini adalah software Partial Least Square (PLS). PLS adalah sebuah alat analisa yang memungkinkan peneliti untuk mendapatkan nilai variabel laten untuk tujuan prediksi. Partial Least Square merupakan metode yang powerful oleh karena tidak didasarkan banyak asumsi. Walaupun PLS dapat digunakan juga untuk mengkonfirmasi teori, tetapi dapat pula digunakan untuk memberikan penjelasan ada atau tidaknya hubungan antar vareiabel laten. Oleh karea menitik beratkan pada data dan dengan prosedur estimasi yang terbatas, maka mispesifikasi model tidak begitu berpengaruh terhadap estimasi parameter (Ghozali, 2014:29).

\section{HASIL DAN PEMBAHASAN}

Untuk menguji convergent validity digunakan nilai outer loading atau loading factor. Suatu indikator dinyatakan memenuhi convergent validity dalam kategori baik apabila memiliki nilai loading factor $>0.50$. Berikut adalah nilai outer loading dari masing-masing indikator pada variabel penelitian:

[Table 1 about here.]

Berdasarkan pengujian convergent validity yang terlihat pada Tabel 1 diatas diketahui bahwa seluruh indikator pada setiap dinyatakan sahih sebagai alat ukur konstrak tersebut sehingga seluruh indikator layak atau valid untuk digunakan dan dapat digunakan untuk analisis lebih lanjut, karena seluruhnya memiliki nilai convergent validity diatas 0,5 .

[Table 2 about here.]

Hasil nilai AVE untuk blok indikator yang mengukur konstruk dapat dinyatakan memiliki nilai discriminant validity yang baik karena nilai AVE $>0,5$. Hal ini berarti bahwa semua variabel konstruk dinyatakan telah memiliki discriminant validity yang baik.

[Table 3 about here.]

Nilai cross loadings pada Tabel 3 di atas dapat diketahui bahwa masing-masing indikator pada variabel penelitian memiliki nilai cross loading terbesar pada variabel yang dibentuknya dibandingkan dengan nilai cross loading pada variabel lainnya. Berdasarkan hasil yang diperoleh tersebut, dapat dinyatakan 
bahwa indikator-indikator yang digunakan dalam penelitian ini telah memiliki discriminant validity yang baik dalam menyusun variabelnya masing-masing.

[Table 4 about here.]

Berdasarkan sajian data pada Tabel 4 di atas, dapat diketahui bahwa nilai composite reliability semua variabel penelitian $>$ 0,70 . Hasil ini menunjukkan bahwa masing-masing variabel telah memenuhi composite realibility sehingga dapat disimpulkan bahwa keseluruhan variabel memadai dalam mengukur variabel laten/konstruk yang diukur sehingga dapat digunakan dalam analisis selanjutnya.

Uji realibilitas dengan composite reliability di atas dapat diperkuat dengan menggunakan nilai cronbach alpha. Suatu variabel dapat dinyatakan reliabel atau memenuhi cronbach alpha apabila memiliki nilai cronbach alpha $>0,6$. Berikut ini adalah nilai Cronbach alpha dari masing-masing variabel:

[Table 5 about here.]

Berdasarkan hasil pengujian pada tabel diatas, dapat diketahui bahwa nilai cronbach alpha dari masing-masing variabel penelitian adalah $>0,60$. Dengan demikian hasil ini dapat menunjukkan bahwa masing-masing variabel penelitian telah memenuhi persyaratan nilai cronbach alpha, sehingga dapat disimpulkan bahwa keseluruhan variabel memiliki tingkat reliabilitas yang tinggi.

Pada penelitian ini untuk menguji hipotesis penelitian digunakan analisis Partial Least Square (PLS) dengan program Smart PLS. Berikut adalah gambar model PLS yang diajukan.

[Figure 1 about here.]

Hasil nilai inner weight Gambar 1 di atas menunjukan bahwa variabel Minat Menjadi Nasabahdipengaruhi oleh variabel Citra Merek, Kepercayaan Merek dan Sikap Merek yang diuraikan pada persamaan struktural $\mathrm{Y}=\mathrm{a}+0.207 \mathrm{X}_{1}+0.253$ $\mathrm{X}_{2}+0.460 \mathrm{X}_{3}+\mathrm{e}_{i}$.
[Table 6 about here.]

Berdasarkan hasil pengujian nilai $R$-square diatas maka dapat diinterpretasikan bahwa Variabel bebas Citra Merek, Kepercayaan Merek, dan Sikap Merek, yang mempengaruhi variabel Minat Menjadi Nasabah memiliki nilai $\mathrm{R}^{2}$ sebesar 0.638 yang mengindikasikan bahwa model "kuat". Hal ini menunjukkan bahwa Citra merek, Kepercayaan Merek dan Sikap Merek kuat dalam mempengaruhi Minat Menjadi Nasabah sehingga hipotesis keempat yang berbunyi "Citra merek, Kepercayaan Merek dan Sikap Merek layak mempengaruhi minat menjadi nasabah tabungan dan giro pada Bank Panin KCP Tambak Langon Surabaya", dinyatakan diterima.

\section{KESIMPULAN}

Berdasarkan hasil analisis yang diperoleh, maka dapat diambil beberapa kesimpulan berikut ini:Citra Merek berpengaruh signifikan terhadap Minat Menjadi Nasabah tabungan dan giro pada Bank Panin KCP Tambak Langon Surabaya. Kepercayaan Merek berpengaruh terhadap Minat Menjadi Nasabah. Sikap merek berpengaruh terhadap minat menjadi nasabah. Citra merek, kepercayaan merek dan sikap merek layak dalam mempengaruhi minat menjadi nasabah tabungan dan giro pada Bank Panin KCP Tambak Langon Surabaya. Berdasarkan hasil analisa dan pembahasan yang dilakukan, peneliti memberikan beberapa saran yang dapat memberikan kontribusi untuk meningkatkan minat menjadi nasabah serta bagi penelitian selanjutnya. Adapun saran-saran tersebut adalah sebagai berikut: Diharapkan Bank Panin KCP Tambak Langon Surabaya lebih meningkatkan reputasi bank yang kemudian akan membangun citra merek bank yang baik bagi nasabah dan meningkatkan minat untuk menjadi nasabah. Diharapkan penelitian selanjutnya yang ingin meneliti dengan topik yang sama supaya dapat menggunakan variabel lainnya yang dapat mempengaruhi tingkat minat menjadi nasabah sehingga dapat mengembangkan hasil penelitian yang telah diperolah dalam penelitian ini.

\section{REFERENSI}

Abdillah, W., dan Jogiyanto. 2015. Partial Least Square (PLS): Alternatif Structural Equation Modeling (SEM) dalam Penelitian Bisnis. Yogyakarta: Andi.

Abrazi, Mehdi, Reza Abahchian Ghassemi, Leila Nasrolahi Vosta. 2014. Analysing the Effect of Social Media on Brand Attitude and Purchase Intention: The Case of Iran Khodro Company. Procedia-Social and Behavioral Sciences 143 (2014) 822-826

Adji, Jennifer dan Hatane Semuel. MS. 2012. Pengaruh Satisfaction dan Trust terhadap Minat Beli Konsumen (Purchase Intention) di Starbucks The Square Surabaya. Universitas Kristen Petra. Jurnal Manajemen Pemasaran Petra Vol. 2, No. 1, (2014) $1-10$

Ahmed, Zohaib et all. 2014. Effect of Brand Trust and Customer Satisfaction on Brand Loyalty in Bahawalpur. Journal of Sociological Research, Vol.5, No. 1.

Al Azzam, Abdel Fattah Mahmoud. (2015). The Impact of Service Quality Dimensions on Customer Satisfaction: A Field Study of Arab Bank in Irbid City, Jordan. European Journal of Business and Management, 17(15). pp. 45-53.

Alma, Buchari. 2011. Manajemen Pemasaran dan Pemasaran jasa. Cetakan 5. Bandung: CV Alfabeta.

Saidani, Basrah, Muh. Siful Muztahid dan Adrian Haro. 2017. The Influence of Perceived Quality, Brand Image, and Emotional 
Value towards Purchase Intention og Consina Backpack. Jurnal Riset Manajemen Sains Indonesia (JRMSI) Vol 8, No. 1. 2017. Bouhlel, O., Nabil M., Doraf H., and Ichrak B.S. 2011. Brand Personality's Influence on the Purchase Intention : A Mobile Marketing Case. International Journal of Business and Management, Vol. 6, No. 9, pp 210-227.

Ferrinadewi, Erna. 2008. Merek dan Psikologi Konsumen. Yogyakarta : Graha Ilmu. Ghozali, 2014. Aplikasi analisis Multivariate dengan Program SPSS. Badan Penerbit UNDIP, Semarang.

Ghozali, Imam. 2016. Aplikasi Analisis Multivariete Dengan Program IBM SPSS 23 (Edisi 8). Cetakan ke VIII. Semarang : Badan Penerbit Universitas Diponegoro.

Kotler, P. \& Keller, K.L. 2012. Manajemen Pemasaran Jilid 1 Edisi ke 12. Jakarta: Erlangga.

Iswara, I Gede Agus Dana dan I Made Jatra. 2017. Peran Brand Image dalam Memediasi Pengaruh Electronic Word of Mouth Terhadap Purchase Intention. E-Jurnal Manajemen Unud, Vol. 6, No. 8. 2017. ISSN: 2302-8912.

Juliansyah, Noor,. 2011. Metodologi Penelitian: Skripsi, Tesis, Disertasi, dan Karya Ilmiah. Jakarta: Kencana.

Muhammad Fahmi Rizanata. 2014. Pengaruh Pelanggan Terhadap Word of Mouth, Niat Beli \& Retensi Pelanggan Gerai Indomaret di Surabaya. Journal of Business and Banking. 1Pp 31-42

Malhotra. 2007. Marketing Research An Applied Orientation. International Edition: Pearson.

Malhotra, N.K. 2012. Basic Marketing Research: Integration of Social Media. Jakarta : PT Index Kelompok Gramedia.

Mamahit, Philius., Agus Supandi Soegoto., dan Willie Alfa Tumbuan. 2015. Pengaruh Brand Image, Brand Trust dan Kualitas Produk terhadap Keputusan Pembelian Mobil Toyota All New Yaris pada PT Hasjrat Abadi Manado. Universitas Sam Ratulangi Manado. Vol. 15, No. 5, Tahun 2015

Manorek, S. L. 2016. The Influeance of Brand Image, advertising, Perceied Price toward Customer Purchase Intention (Case Study : Samsung Smartphone). 16(1), 661-670.

Republik Indonesia. 1998. Undang-Undang No.10 Tahun1998 Tentang Perbankan. Jakarta.

Shabbir, Muhammad Qasim., Khan, Anshar Ali., Khan, Saba Rasheed (2017). Brand Loyalty, Brand Image and Brand Equity : The Mediating Role of Brand Awereness. International Journal of Innovation and Applied Studies, Vol. 19 No. 2 Feb. 2017, pp. 416-423.

Semuel, Hatane dan Adi Suryanata Lianto. 2014. Analisis eWom, Brand Image, Brand Trust dan Minat Beli Produk Smartphone di Surabaya. Universitas Kristen Petra. Jurnal Manajemen Pemasaran, Vol. 8,No. 2, Oktober 2014. ISSN 1907-235X

Sugiyono. 2011. Metode Penelitian Kuantitatif, Kualitatif dan R\&D. Bandung: Alfabeta

Sugiyono, 2012. Metode Penelitian Kuantitatif, Kualitatif, dan R\&D. Bandung: Alfabeta.

Sugiyono. 2013. Metode Penelitian Bisnis. Bandung: Alfabeta.

Sugiyono. 2016. Metode Penelitian Kuantitatif, Kualitatif dan R\&D. Bandung: PT Alfabet.

Supardi. 2013. Aplikasi Statistika dalam Penelitian Konsep Statistika yang Lebih Komprehensif. Jakarta: Change Publication.

Sutisna. 2012. Perilaku Konsumen dan Komunikasi Pemasaran. Bandung: PT Remaja Rosdakarya.

Syed Saad Hussain Shah,Jabran Aziz, Ahsan Raza Jaffari, Sidra Waris,Wasiq Ejaz, Maira Fatima and Syed Kamran Sherazi. 2012. The Impact of Brands on Consumer Purchase Intention. Asian Journal of Business Management 4(2): 105-110. ISSN: 20418752

Vidyanata, Deandra, Sunryo dan Djumilah Hadiwijojo. 2018. The Role of Brand Attitude and Brand Credibility as a Mediator of The Celebruty Endorsement Strategy To Generate Purchase Intention. Journal of Applied Management (JAM). Vol. 16, No. 3, September 2018

Conflict of Interest Statement: The authors declare that the research was conducted in the absence of any commercial or financial relationships that could be construed as a potential conflict of interest.

Copyright $(2020 \mathrm{Al}$ Azis and Harsono. This is an open-access article distributed under the terms of the Creative Commons Attribution License (CC BY). The use, distribution or reproduction in other forums is permitted, provided the original author(s) and the copyright owner(s) are credited and that the original publication in this journal is cited, in accordance with accepted academic practice. No use, distribution or reproduction is permitted which does not comply with these terms. 


\section{LIST OF FIGURES}

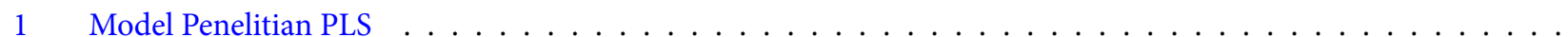




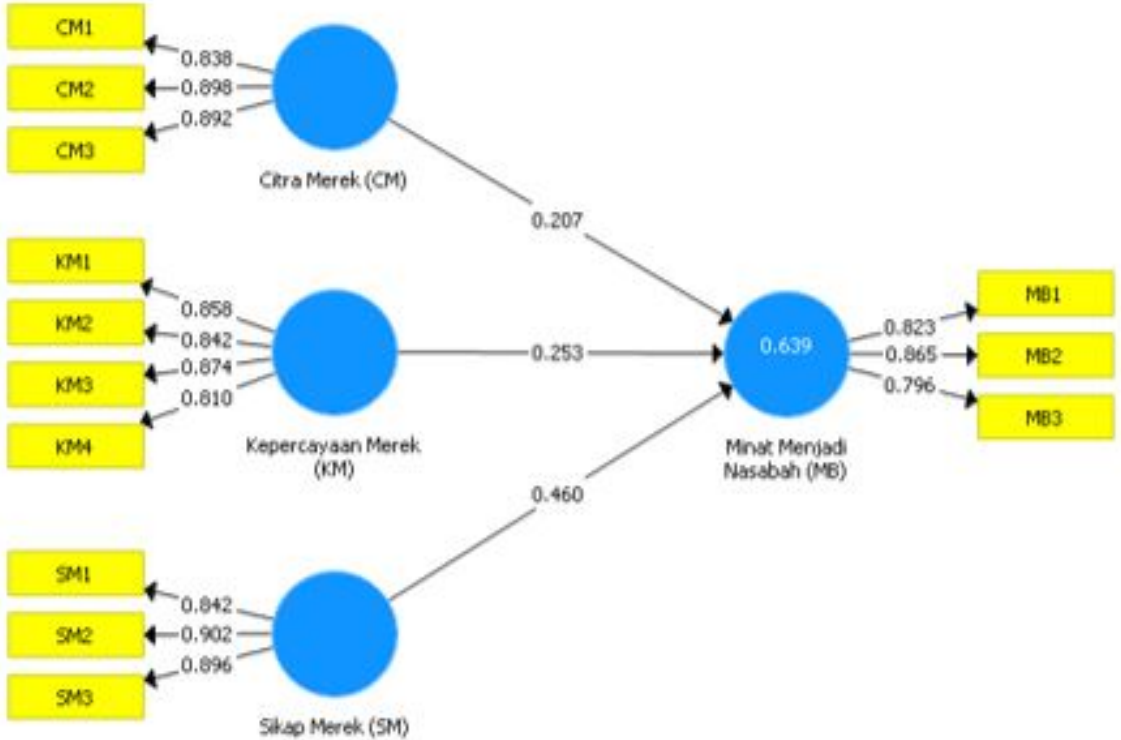

FIGURE 1 | Model Penelitian PLS 


\section{LIST OF TABLES}

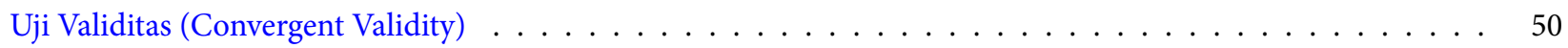

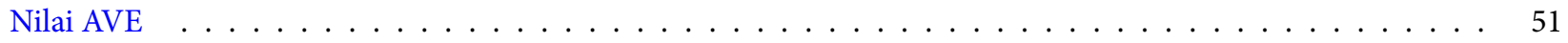

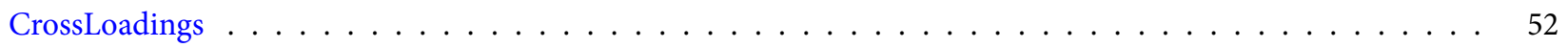

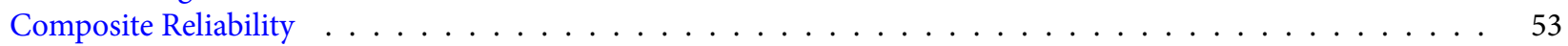

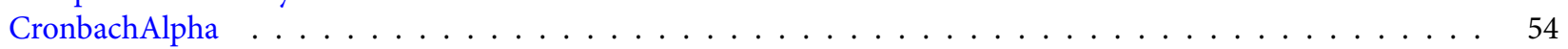

HasilPengujian Hipotesis . . . . . . . . . . . . . . . . . . . . . . . . . 55 
TABLE 1 | Uji Validitas (Convergent Validity)

\begin{tabular}{lll}
\hline Variabel & original sample estimate & Keterangan \\
\hline Citra & 0.838 & Valid \\
Merek & 0.898 & Valid \\
(X1) & 0.892 & Valid \\
& 0.858 & Valid \\
Kepercayaan & 0.842 & Valid \\
Merek & 0.874 & Valid \\
(X2) & 0.810 & Valid \\
& 0.842 & Valid \\
Sikap & 0.902 & Valid \\
Merek & 0.896 & Valid \\
(X3) & 0.823 & Valid \\
Minat & 0.865 & Valid \\
Menjadi & Valid \\
Nasabah & 0.796 & \\
(Y) & &
\end{tabular}


TABLE 2 | Nilai AVE

\begin{tabular}{ll}
\hline Variabel & Average Variance Extracted (AVE) \\
Citra Merek (X1) & 0.768 \\
Kepercayaan Merek (X2) & 0.716 \\
Sikap Merek (X3) & 0.775 \\
Minat Menjadi Nasabah (Y) & 0.687 \\
\hline
\end{tabular}


TABLE 3 | CrossLoadings

\begin{tabular}{lllll}
\hline & Citra Merek $(X 1)$ & Kepercayaan Merek $(X 2)$ & Sikap Merek $(X 3)$ & Minat Menjadi Nasabah $(Y)$ \\
CM1 & 0.838 & 0.336 & 0.558 & 0.486 \\
CM2 & 0.898 & 0.339 & 0.551 & 0.535 \\
CM3 & 0.892 & 0.417 & 0.611 & 0.588 \\
KM1 & 0.304 & 0.858 & 0.515 & 0.547 \\
KM2 & 0.296 & 0.842 & 0.418 & 0.448 \\
KM3 & 0.411 & 0.874 & 0.588 & 0.530 \\
KM4 & 0.390 & 0.810 & 0.632 & 0.606 \\
SM1 & 0.526 & 0.555 & 0.842 & 0.668 \\
SM2 & 0.601 & 0.581 & 0.902 & 0.670 \\
SM3 & 0.602 & 0.570 & 0.896 & 0.668 \\
MB1 & 0.452 & 0.549 & 0.620 & 0.823 \\
MB2 & 0.497 & 0.505 & 0.630 & 0.865 \\
MB3 & 0.573 & 0.529 & 0.636 & 0.796 \\
\hline
\end{tabular}


TABLE 4 | Composite Reliability

\begin{tabular}{ll} 
Variabel & Composite Reliability \\
Citra Merek (X1) & 0.908 \\
Kepercayaan Merek (X2) & 0.910 \\
Sikap Merek (X3) & 0.912 \\
Minat Menjadi Nasabah (Y) & 0.868 \\
\hline
\end{tabular}


TABLE 5 | CronbachAlpha

\begin{tabular}{ll} 
Variabel & Cronbach Alpha \\
Citra Merek (X1) & 0.849 \\
Kepercayaan Merek (X2) & 0.868 \\
Sikap Merek (X3) & 0.854 \\
Minat Menjadi Nasabah (Y) & 0.771 \\
\hline
\end{tabular}


TABLE 6 | HasilPengujian Hipotesis

\begin{tabular}{lllll}
\hline & Original Sample & Sample Mean & Standard Deviation & Statistics $(|\mathrm{O} / \mathrm{STDEV}|)$ \\
Citra Merek (X1) -> Minat Menjadi Nasabah (Y) & 0.207 & 0.209 & 0.059 & 3.496 \\
Kepercayaan Merek (X2) -> Minat Menjadi Nasabah (Y) & 0.253 & 0.256 & 0.059 & 4.293 \\
Sikap Merek (X3) -> Minat Menjadi Nasabah (Y) & 0.460 & 0.453 & 0.058 & 7.878 \\
\hline
\end{tabular}

